\title{
STRUCTURAL CHANGE IN REGIONAL LABOR MARKETS: THE AUSTRALIAN EXPERIENCE OF THE SEVENTIES
}

\author{
Philip Maxwell and Mark Wilson*
}

\section{Introduction}

In the same way as other Western economies, Australia experienced significant change in its economic structure during the seventies. An important part of this change occurred in the work force. While the officially estimated number of people in the labor force increased from about 5.5 million in 1970 to 6.5 million in 1980 , the rate of growth varied widely between different sectors. Also, the level of unemployment estimated by the Australian Bureau of Statistics grew from less than two percent of the labor force to more than six percent. As in a number of other industrialized countries, the major decline in employment occurred in manufacturing and the major gain in the final services sector. Employment in agriculture, mining and the intermediate services field showed little variation in percentage terms.

As might be expected under these circumstances, the issue of structural change and adjustment became prominent in national economic debate in both government and academic circles. The federal government initiated several studies, and professional bodies conducted a number of seminars and symposia on the topic. ${ }^{1}$ In particular, much of the early discussion of the structural change problem focused on the way in which internal and external influences affected the national situation. Only more recently has attention been focused at the subnational regional level. While international influences remain important here, the nature of the urban hierarchy and its effect on regional interrelationships plays a significant role in determining the nature of the geographical pattern of the structural change process.

During Australia's economic prosperity of the 1950 s and 1960 s, it was generally possible

*Deakin University, Geelong, Australia and University of Pennsylvania, Philadelphia, respectively. for all regions to claim some share of national growth, but the past decade has been one where regional specialization and endowment have led to divergence. In periods of slower growth of economic activity, peripheral regions previously on the perimeter of development often experience major structural adjustment problems. Regions most able to adapt to such conditions are usually those offering either diversified economic bases or rich resource endowments, or both. In Australia these areas are represented by the largest urban centers, and mining or resource processing regions.

A major purpose of this study is to review the ways in which regional and national factors influenced the structural change which occurred in regional labor markets in Australia during the seventies. Before ernbarking on any empirical analysis, it is important to consider the regional nature of the structural change process and to relate this to Australia's substate regional structure. This is done in the next section. This is followed by a discussion of the problems faced in measuring structural change and the necessity to match available measures with appropriate data. Empirical results derived from a simple model are then presented, and some concluding comments made.

\section{Regional Development and Structural Change}

Structural change is a gradual and continuous process representing the adjustment by components of the economy to differing stimuli and the effects of changes in other parts of the economy; it is the product of feedback within the economic system. As an economy develops there are many interactive forces operating, propelling it from one state to the next with the progression from agriculture to manufacturing to services a general illustration of structural change. 
Because invention, innovation and resource endowments are not evenly distributed in a spatial sense, development occurs differently at international, national, state and sub-state regional levels. Two aspects which stand out as influencing the process are the nature of a country's urban hierarchy and the somewhat "random" allocation of its mineral and agricultural resources which attract activity because they are key inputs for final production. The influence of the urban hierarchy merits detailed discussion.

Large cities tend to lead the development process as the sources of new activities and production systems. They fulfill this function because they provide a social and economic infrastructure amenable to change and consequently greater opportunities for entrepreneurs, labor and capital. Aiding this environment is the concentration of research and development facilities located in large metropolitan areas (Pred, p. 17). The economic development which begins in large cities gravitates to smaller centers and their regions. There are several reasons for this flow of activity. One is that cities of similar sizes tend to be interrelated in terms of communication, so that the next largest cities are usually the first to adopt an idea after its initial development. Another is that as a new commodity's production system is refined, its cost tends to decrease along with the routinization of production allowing a smaller threshold market to be supported, so that smaller centers attract these actitivies (Mansfield, p. 139).

The passage of invention and innovation between members of the urban hierarchy operates to perpetuate the system, with the largest cities performing the most advanced work, spinning it off when it becomes routine, and then adopting new functions in their early stages of development (Stanback and Knight, pp. 103-155). Because large urban economies perform a broad range of economic activities, they are somewhat insulated from economic fluctuations. By contrast, smaller non-metropolitan regions which rely on a narrow range of industries are often subject to considerable economic stress, particularly when they contain slow growth sectors.

The extent of structural change at a regional level is a function of the development process and the urban hierarchy. These factors operate to spread change within an economy and changes in economic structure are a by-product of the diffusion of development. Regions in a steady state or growing slowly will experience little structural change unless their economic base is particularly subject to business cycle fluctuations. At the other extreme are regions undergoing significant change as a result of rapid development. Part of the different experience between regions will be attributable to their geographical proximity to major centers. Where isolated areas depend on mature industrial bases, the speed of transmission of the development process will be slowed.

Another important factor influencing structural change is the type of regional ecomomy. While the hierarchy serves to integrate each region within the national framework, when this has occurred local factors often emerge as further generators of economic change.

Recently, the development of new ideas and processes has become less dependent upon the urban hierarchy as improved communication and greater integration lead to rapid diffusion independently of urbanization. Leading centers are not necessarily the source of all new ideas, and distance from these cities does not preclude development, as was often the case in the past. The hierarchy undergoes change along with the economy, so that its operation must be reassessed at different stages of development if it is to remain a valid explanatory variable.

From the preceding discussion it is clear that those forces which determine the regional pattern of structural change in an economy are complex. ${ }^{2}$ Despite this it is convenient to characterize the process as being dependent on three main factors-the nature of the development process, the urban hierarchy and a series of local factors. Factors such as technological change, the world recession, the escalation of labor costs and changes in government policy which have been suggested as important determinants of structural change at a national level in Australia in the seventies, impinge on and influence the urban hierarchy and the development process.

In terms of urban hierarchy the Australian economy can be classified as containing a heavily populated core and a remainder consisting of sparsely populated and isolated agricultural and mining regions. The first area consists of regions in the Sydney-Melbourne corridor with extensions to Brisbane and Adelaide. Every region in this area lies in a major transport corridor, i.e., on a main highway or railway line or 
both. Perth also operates as a part of this group-see Figure 1. This core, which contains nearly 90 percent of Australia's population, concentrates on services in all the cities, manufacturing in certain specified cities and provincial towns e.g. Melbourne, Sydney, Newcastle, Wollongong, Geelong etc., and agriculture in its nearby hinterland.

An important local factor operating in several isolated regions as a generator of structural change is the existence of mining activity. Key mining regions such as Port Hedland, Kalgoorlie and Geraldton in Western Australia, the North West of Queensland and the Far West in New South Wales experienced significant change to their economic structures both as a result of the boom in the early part of the decade, and the subsequent recession.

\section{A Framework for Empirical Analysis}

Empirical assessment of structural change among regions requires both a clear definition of regional boundaries and an appropriate definition of a measure. Let us consider each in turn.

One possible regional classification is to divide Australia into its six states. Because of their relative homogeneity, and also because this grouping is too large to effectively identify the impact of the key variables mentioned above on the structural change process, the adoption of a sub-state regional classification seemed more appropriate.

In defining regional boundaries we have therefore adhered closely to a classification suggested by the Australian Government's Depart-

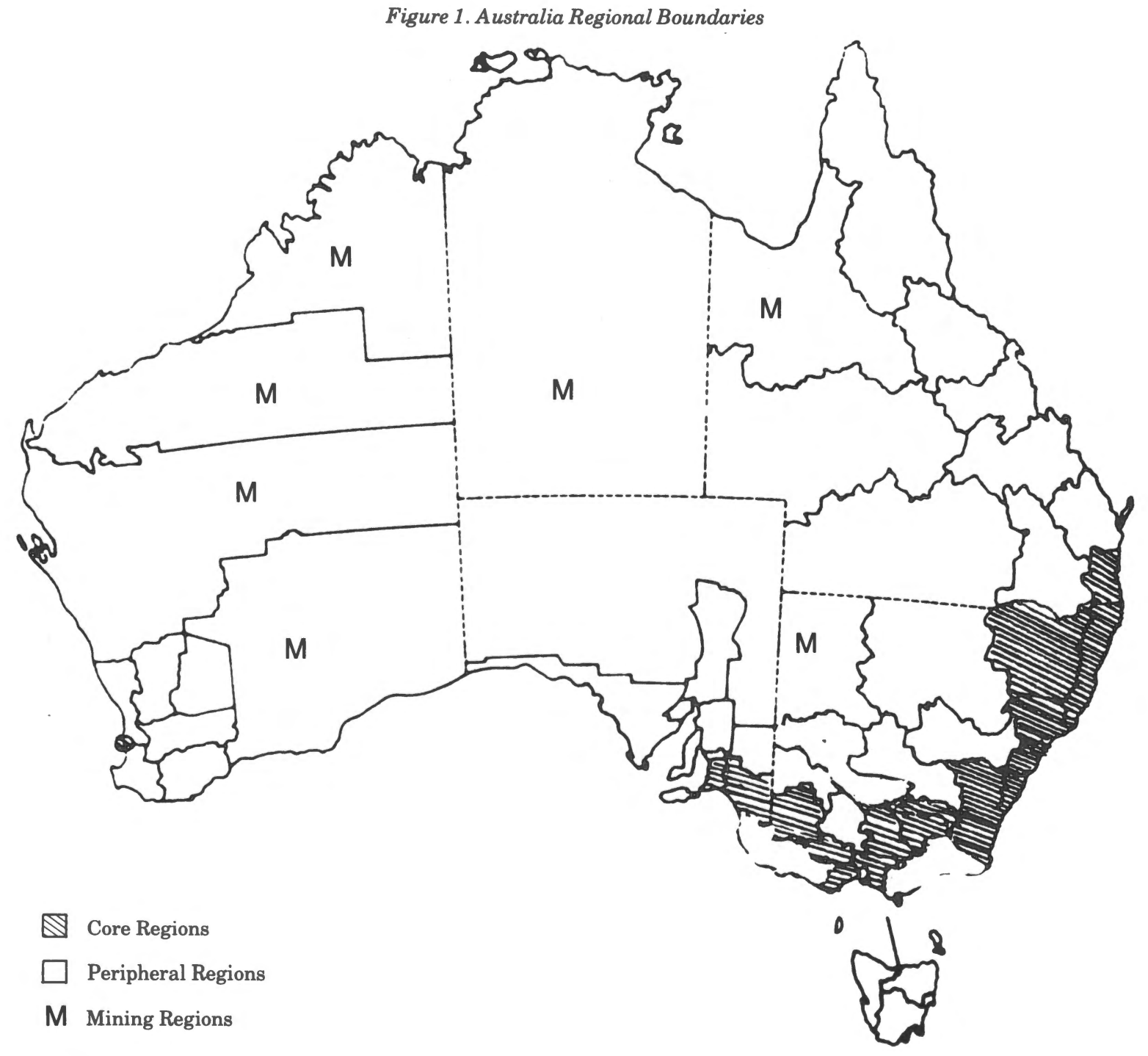



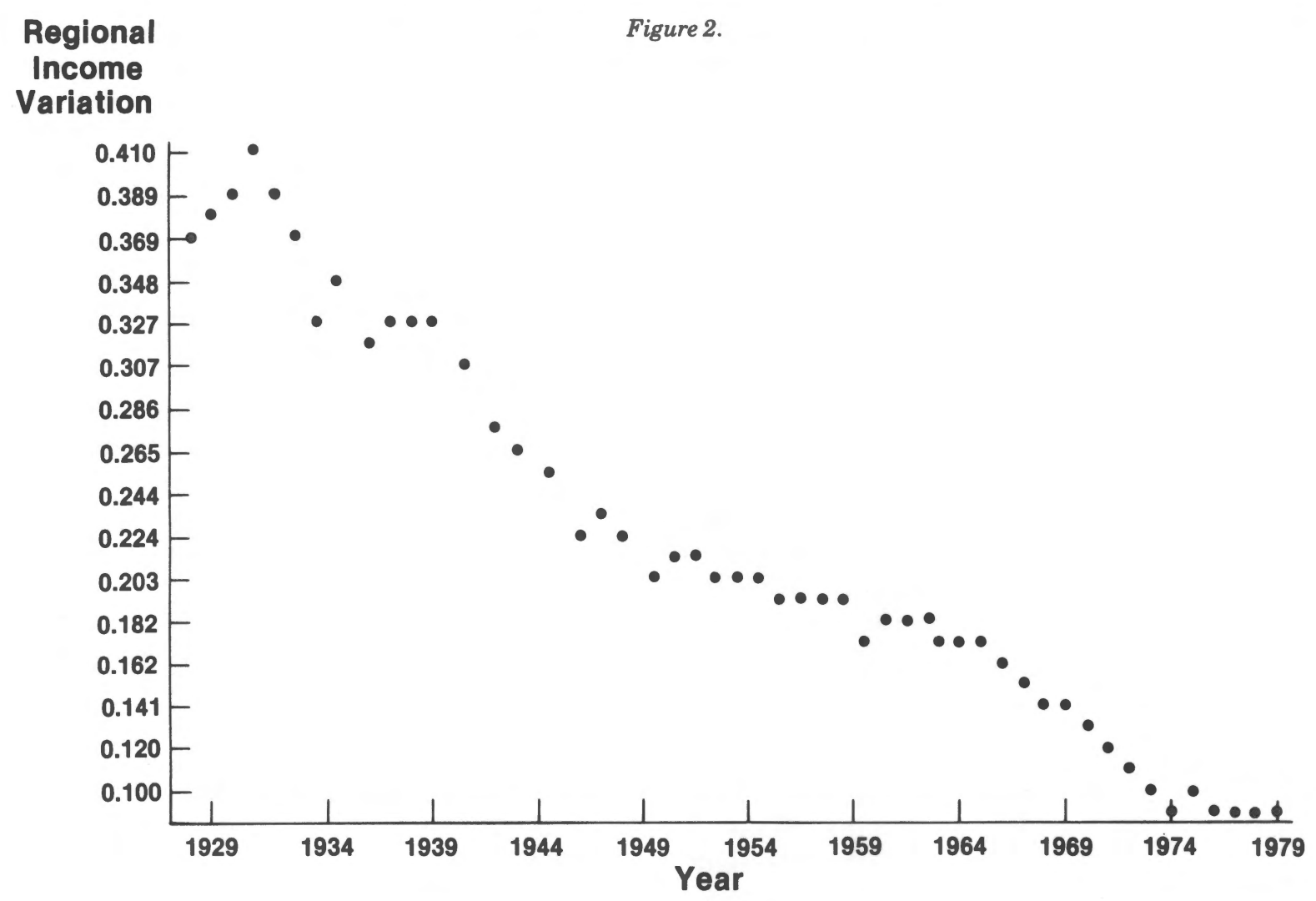

ment of Urban and Regional Development in 1973. It divided Australia into 68 sub-state regions. These consisted of 16 in New South Wales, 18 in Victoria, 10 in Queensland, 11 in South Australia, 10 in Western Australia and 3 in Tasmania. If the Australian Capital Territory and the Northern Territory are added to this, one obtains a total of 70. Within this Sydney was divided into five regions, Melbourne into eight regions, and Adelaide into a metropolitan region with an outer metropolitan ring region. If one argues that Sydney, Melbourne and Adelaide should each be considered as single regions, and includes the A.C.T. and the Northern Territory, the total falls to 58 . We have adopted this convention.

In deriving a suitable measure, a good case can be made for equating structural change with changes in the allocation of productive resources. This reflects movement between products and locations and of employees changing their positions. A lack of data precluded the complete adoption of this approach, although a useful representation of the structure of an economy can be gained from analysis of its employment by industry and occupation. Changes in employment, particularly on an occupational basis, indicate labor turnover and shifts in the demand for different job skills. A simple yet appealing measure based on employment movements is the SC measure (Schiavo-Campo). ${ }^{3}$ In his words it is

"... the sum of the absolute value of changes in each sub-group's percentage share in the category under examination, divided by two, in order to avoid doublecounting of share changes" (p. 261).

The relevant formula is

$$
\mathrm{SC}=50 \Sigma\left|\mathrm{m}_{\mathrm{it}}-\mathrm{m}_{\mathrm{i}(\mathrm{t}+\mathrm{k}}\right|
$$

where $m_{i t}=$ share of the ith sub-group in period $t$,

and $\mathrm{m}_{\mathrm{i}(\mathrm{t}+\mathrm{k})}=$ share of the its subgroup in period $\mathbf{t}+\mathbf{k}$.

The measure has several appealing features. One of these is that it converts changes in structure to a single measure which may range in its value between zero and 100. Comparison of the magnitude of percentage changes in employment, unemployment, etc., is enhanced by such an index. A second feature is that the index can be simply broken into different component parts if this is considered useful to facilitate analysis.

Balanced against this is the common prob- 
lem, faced with other such indicators, that the size of the index is directly influenced by the level of detail of the structural classification used. Another potential weakness may arise from the non-parametric nature of the index which makes comparison difficult with measures which have given distributions.

Since information on the work force is available at each national census for Australian substate regions, it is convenient to view structural change in terms of movements in labor force activity during intercensal periods. At each census the Australian Bureau of Statistics publishes comprehensive data on employment by both industry class and occupational groupings. It also produces unemployment data and data on population of working age who are not in the labor force. Two national censuses were taken in the seventies-in 1971 and in 1976.

Four versions of the SC index have been estimated for regional labor force data during the 1971-1976 period. The first two are based on the one-digit Australian Standard Industry Classification (ASIC) code first used at the 1971 census. The final two are based on the one-digit Australian Standard Occupational Classification (ASOC) code.

The first measure-(SCEI) - is an SC index for employment by industrial group. Its computation involved cumulating absolute percentage differences between employment in the twelve basic industry classes-agriculture; mining; manufacturing; electricity, gas and water; construction; transport and storage; communications; wholesale and retail trade; finance; public administration; community services; and entertainment. Employed respondents not stating their industry class or otherwise not classified were proportionately distributed to each of the other industrial groups.

The second measure-(SCPI)-was computed in a similar manner but also includes the percentage level of unemployment, and people aged between 15 and 64 years not in the workforce, in the total. ${ }^{4}$ Because it considers all of the labor force and takes account of the effects of movements into and out of it this is in certain respects a more appealing index.

The third and fourth measures-SCEO and $\mathrm{SCPO}^{5}$ - are based on cumulating absolute percentage changes in employment in the ten ASOC occupational classes-professional; administrative; clerical; sales; farmers and related occupations; miners; transport and communication; tradesmen, laborers and production process workers; service, sport and recreation; and the armed services. SCPO additionally includes the effect of changes in the percentage levels of unemployment, and in the percentage of people aged 15 to 64 years not in the workforce. For similar reasons to those discussed above with respect to SCEI and SCPI, $\mathrm{SCPO}$ is in certain aspects a more appealing index than SCEO.

Table 1 contains estimates of SCEI, SCEO, SCPI, and SCPO on a regional basis. Also included are estimates of the contribution to the population based SC measures of changes in those people of working age who are not employed.

Additionally in Table 1 we classify each region in accordance with several economic or spatial characteristics. Specifically, regions are identified in the following categories: capital city regions $(\mathrm{K})$, core regions $(\mathrm{C})$, agricultural regions (A), manufacturing regions $(\mathrm{F})$, mining regions (M) and growth-center regions (G). Agricultural, manufacturing and mining regions are identified on the basis of significant percentage employment levels in each of these industry sectors at the 1971 Census. Agricultural regions are those with more than 20 percent of employment in farming and related activities, manufacturing regions those with more than 25 percent of factory employment, and mining regions those with more than ten percent employed in mineral extraction and exploration. While the cut-off points in this categorization are somewhat arbitrary, they accord with widely held perceptions of the major contributions made by each industry type to the economic well being of the regions concerned.

The growth center classification applies only to two regions-North Eastern in Victoria and Murray in New South Wales. The city of Albury-Wodonga, the only survivor from an ambitious federally funded growth-center program which began in the early seventies, is located in these adjoining regions.

The varying experiences of selected categories of regions are compared further in Table 2 . The seven capital city regions on average experienced greater apparent change in their employment structure between 1971 and 1976 than the overall national experience (see Table 1) using all SC measures estimated. When com- 
TABLE 1

Estimates of the SC Index By Sub-State Regions In Australia 1971-1976

\begin{tabular}{|c|c|c|c|c|c|c|}
\hline \multirow[b]{2}{*}{ Region } & \multirow{2}{*}{$\begin{array}{c}\text { Region } \\
\text { Type* }\end{array}$} & \multicolumn{2}{|c|}{ Employment Data } & \multicolumn{2}{|c|}{$\begin{array}{l}\text { All Population of } \\
\text { Working Age Data }\end{array}$} & \multirow{2}{*}{$\begin{array}{l}\text { Contribution to } \\
\text { SCPI and SCPO } \\
\text { of Non-Employed }\end{array}$} \\
\hline & & SCEI & SCEO & SCPI & $S C P O$ & \\
\hline \multicolumn{7}{|c|}{ NEW SOUTH WALES } \\
\hline Sydney & $\mathrm{KCF}$ & 5.75 & 3.70 & 5.28 & 4.00 & 1.90 \\
\hline North Coast & $\mathrm{CA}$ & 6.39 & 5.75 & 5.81 & 6.90 & 2.61 \\
\hline New England & $\mathrm{CA}$ & 4.33 & 3.20 & 4.43 & 5.00 & 1.46 \\
\hline Orana & $\mathbf{A}$ & 4.23 & 2.95 & 6.82 & 8.10 & 3.61 \\
\hline Far West & $\mathbf{M}$ & 7.12 & 3.85 & 4.82 & 2.95 & 0.91 \\
\hline Murray & CAG & 7.53 & 6.60 & 6.49 & 7.70 & 2.80 \\
\hline Riverina & A & 3.30 & 2.35 & 5.01 & 4.70 & 2.76 \\
\hline Central West & A & 3.65 & 2.75 & 5.80 & 5.50 & 3.48 \\
\hline South East & CA & 4.48 & 2.95 & 5.69 & 4.60 & 2.96 \\
\hline Hunter & $\mathrm{CF}$ & 4.48 & 3.70 & 4.43 & 4.30 & 2.08 \\
\hline Gosford-Wyong & $\mathrm{C}$ & 6.38 & 5.40 & 6.50 & 3.85 & 4.10 \\
\hline Illawarra & CF & 5.02 & 3.70 & 5.12 & 4.45 & 2.25 \\
\hline \multicolumn{7}{|l|}{ VICTORIA } \\
\hline Melbourne & KCF & 4.65 & 4.00 & 4.57 & 3.05 & 1.83 \\
\hline Barwon & CF & 3.95 & 2.70 & 6.16 & 6.35 & 4.10 \\
\hline South Western & A & 3.82 & 2.55 & 5.33 & 5.25 & 3.46 \\
\hline Central Highlands & C & 4.47 & 2.75 & 5.98 & 5.10 & 3.41 \\
\hline Wimmera & CA & 3.95 & 2.85 & 6.18 & 6.10 & 3.15 \\
\hline Northern Mallee & $\mathbf{A}$ & 3.26 & 3.60 & 6.53 & 6.00 & 4.11 \\
\hline Loddon Campaspe & A & 4.90 & 4.60 & 5.47 & 6.20 & 3.34 \\
\hline Goulburn & $\mathrm{CA}$ & 4.70 & 5.15 & 5.86 & 6.45 & 3.45 \\
\hline North Eastern & CAG & 8.00 & 6.85 & 6.91 & 7.60 & 2.90 \\
\hline East Gippsland & A & 6.28 & 6.65 & 7.31 & 6.90 & 2.78 \\
\hline Central Gippsland & $\mathbf{A}$ & 5.48 & 3.75 & 6.07 & 5.70 & 3.10 \\
\hline \multicolumn{7}{|l|}{ TASMANIA } \\
\hline Southern & $\mathbf{K}$ & 7.58 & 4.95 & 6.06 & 4.35 & 1.70 \\
\hline Mersey-Lyell & $\mathbf{M}$ & 5.55 & 3.70 & 4.67 & 3.65 & 1.45 \\
\hline Northern & & 5.49 & 3.40 & 4.92 & 3.55 & 1.23 \\
\hline \multicolumn{7}{|l|}{ QUEENSLAND } \\
\hline Moreton & $\mathrm{KC}$ & 5.96 & 4.05 & 5.70 & 4.00 & 2.57 \\
\hline Wide Bay-Burnett & $\mathbf{A}$ & 5.49 & 4.70 & 5.42 & 5.50 & 2.66 \\
\hline Fitzroy & & 5.14 & 5.90 & 5.03 & 5.15 & 2.26 \\
\hline Mackay & $\mathbf{A}$ & 7.11 & 3.45 & 7.48 & 5.50 & 3.29 \\
\hline Northern & & 3.70 & 2.65 & 6.14 & 5.95 & 3.31 \\
\hline Far North & & 5.06 & 4.45 & 6.01 & 5.25 & 2.95 \\
\hline North West & $\mathbf{M}$ & 13.79 & 5.80 & 11.55 & 5.95 & 2.31 \\
\hline Central West & $\mathbf{A}$ & 3.63 & 2.80 & 5.65 & 4.85 & 2.66 \\
\hline South West & $\mathbf{A}$ & 4.84 & 2.20 & 7.12 & 6.15 & 3.63 \\
\hline Darling Downs & $\mathbf{A}$ & 6.70 & 2.55 & 6.45 & 3.65 & 2.13 \\
\hline \multicolumn{7}{|c|}{ SOUTH AUSTRALIA } \\
\hline Adelaide & $\mathrm{KCF}$ & 5.41 & 3.50 & 5.09 & 3.95 & 2.09 \\
\hline Kangaroo Island & A & 6.68 & 3.80 & 9.85 & 7.70 & 3.94 \\
\hline Murray Mallee & $\mathrm{CA}$ & 6.11 & 4.30 & 8.87 & 7.35 & 3.73 \\
\hline South East & A & 3.39 & 3.75 & 6.55 & 7.55 & 3.73 \\
\hline Upper Murray & A & 4.91 & 4.10 & 7.67 & 6.70 & 3.61 \\
\hline Mid North & A & 9.74 & 8.90 & 9.87 & 7.30 & 3.94 \\
\hline Yorke Peninsula & A & 5.67 & 5.35 & 7.40 & 7.40 & 3.55 \\
\hline Whyalla & $\mathbf{F}$ & 8.41 & 2.25 & 7.64 & 4.10 & 2.67 \\
\hline Eyre & $\mathbf{A}$ & 5.37 & 4.20 & 9.32 & 7.10 & 4.38 \\
\hline Flinders Ranges & & 10.00 & 6.50 & 9.36 & 6.45 & 2.62 \\
\hline
\end{tabular}


TABLE 1. Continued

\begin{tabular}{|c|c|c|c|c|c|c|}
\hline \multirow[b]{2}{*}{ Region } & \multirow{2}{*}{$\begin{array}{c}\text { Region } \\
\text { Type* }\end{array}$} & \multicolumn{2}{|c|}{ Employment Data } & \multicolumn{2}{|c|}{$\begin{array}{l}\text { All Population of } \\
\text { Working Age Data }\end{array}$} & \multirow{2}{*}{$\begin{array}{l}\text { Contribution to } \\
\text { SCPI and SCPO } \\
\text { of Non-Employed }\end{array}$} \\
\hline & & SCEI & SCEO & $S C P I$ & SCPO & \\
\hline \multicolumn{7}{|l|}{ WESTERN AUSTRALIA } \\
\hline Perth & $\mathbf{K C}$ & 5.05 & 3.55 & 3.77 & 3.50 & 1.89 \\
\hline Albany & A & 4.43 & 3.20 & 6.83 & 7.25 & 3.48 \\
\hline Bunbury & A & 4.27 & 3.85 & 4.43 & 4.80 & 2.53 \\
\hline Geraldton & $\mathrm{AM}$ & 10.19 & 5.20 & 7.50 & 5.30 & 2.10 \\
\hline Kalgoorlie & $\mathbf{M}$ & 13.29 & 4.20 & 6.50 & 3.60 & 1.17 \\
\hline Merredin & A & 6.72 & 3.05 & 10.08 & 8.10 & 4.76 \\
\hline Narrogin & A & 7.38 & 6.35 & 9.48 & 7.90 & 4.46 \\
\hline Northam & A & 9.06 & 5.50 & 10.68 & 7.85 & 4.81 \\
\hline Port Hedland & $\mathbf{M}$ & 24.30 & 9.15 & 14.44 & 8.45 & 2.31 \\
\hline Wyndham & $\mathbf{A M}$ & 19.99 & 11.55 & 10.60 & 9.15 & 2.23 \\
\hline AUSTRALIAN & & & & & & \\
\hline CAPITAL TERRITORY & $\mathrm{KC}$ & 3.48 & 2.80 & 4.86 & 4.30 & 2.04 \\
\hline \multicolumn{7}{|l|}{ NORTHERN } \\
\hline TERRITORY & & 9.60 & 7.80 & 6.47 & 6.30 & 0.97 \\
\hline AUSTRALIA & & 4.15 & 3.15 & 3.45 & 2.65 & 1.00 \\
\hline
\end{tabular}

*Region Type Key. $\mathrm{K}$ - capital city region, $\mathrm{C}$ - core region, A - agricultural region, $\mathrm{F}$ - manufacturing region, $\mathrm{M}$ - mining region, $\mathbf{G}$ - growth centre region.

pared with agricultural and mining regions, however, less structural change appeared to take place. While SC measures based only on employment were less on average in manufacturing centers than in capitals, they were greater when based on all population of working age.

A review of the SCPI and SCPO estimates in

TABLE 2

Summary of SC Index Values By Sub-State Region Type Australia 1971-1976

\begin{tabular}{lrrrr}
\hline & SCEI & SCEO & SCPI & SCPO \\
\hline $\begin{array}{l}\text { Capital City Regions (7) } \\
\quad \text { Mean }\end{array}$ & 5.41 & 3.79 & 5.04 & 3.88 \\
$\quad$ Standard Deviation & 1.16 & 0.61 & 0.70 & 0.42 \\
& & & & \\
Core Regions (18) & 5.28 & 4.15 & 5.77 & 5.24 \\
$\quad$ Mean & 1.22 & 0.74 & 1.15 & 1.47 \\
$\quad$ Standard Deviation & & & & \\
Agricultural Regions* (34) & 5.49 & 4.22 & 6.96 & 6.42 \\
$\quad$ Mean & 1.66 & 1.59 & 1.69 & 1.20 \\
$\quad$ Standard Deviation & & & & \\
$\quad$ Manufacturing Regions (7) & & & & \\
$\quad$ Mean & 5.27 & 3.29 & 5.53 & 4.41 \\
$\quad$ Standard Deviation & 1.30 & 0.59 & 0.90 & 0.91 \\
$\quad$ Mining Regions (7) & & & & \\
$\quad$ Mean & 12.98 & 6.41 & 8.32 & 5.67 \\
$\quad$ Standard Deviation & 5.99 & 2.66 & 3.28 & 2.12 \\
\hline
\end{tabular}

*excluding those regions which also have high levels of mining activity viz. Geraldton and Wyndham. both tables indicate some interesting trends. While increases in the unemployment rate and decreases in the percentage of working age population made significant contributions to the values of these measures in capital cities, their contribution tended to be even larger for agriculturally dependent hinterland regions. The net result was that the value of the indices for these regions usually exceeded those for the capital cities. In mining regions, by contrast, changes in unemployment and labor force participation were relatively small. When combined with the larger variations in employment by industry and occupation, the SCPI and SCPO values in these regions tended to become comparable with the corresponding values in capital cities.

\section{A Simple Model and Empirical Results}

Replication of the operation of the Australian regional economy must be delayed until greater insight into its functioning occurs, and more detailed data on prices, wages and population movement is available. To provide one view of part of this process, a series of models have been specified which incorporate the major factors, i.e., the development process, the urban hierarchy and local factors, thought to explicitly explain variations in structural change measures. While it is a relatively straightforward 
task to obtain data-reflecting local factors and a region's position with respect to the urban hierarchy, there is a significant challenge involved in deriving appropriate data to explain the development process in a regional context.

When the 1971 Census was taken, Australia was in a period of high economic activity and a mining boom was in progress. Investment spending was high, particularly in the isolated newly developing mining areas. Employment levels were similarly high in the construction industry in these locations. In 1976, by contrast, the nation was in recession and the building industry had been particularly hard hit. The decline in construction activity was a significant component of the SC index in developing regions. It might be argued, therefore, that the initial percentage level of construction activity in a region is an effective surrogate for the effect of the recession on change in its employment structure.

Another variable reflecting the development process in a regional context is employment growth. One hypothesis worthy of consideration is that high employment growth is more likely to occur in regions with a healthy initial workforce structure. Such regions will be subject to minimal structural change. By contrast, regions with a mature industrial base whose workforce is static or declining seem likely to experience substantial change in recessionary periods, especially if their production is in commodities with relatively high demand elasticities.

To analyze the structural change indices for industrial and occupational employment data alone, we specified two single equation models containing elements reflecting the state of the development process, urban hierarchy and local factors. Their general form is as follows:

$$
\begin{aligned}
\text { SCEI } & =\mathrm{f}(\mathrm{dw} / \mathrm{dt}, \mathrm{B}, \mathrm{C}, \mathrm{A}, \mathrm{M}, \mathrm{G}) \\
\text { and SCEO } & =\mathrm{F}(\mathrm{dw} / \mathrm{dt}, \mathrm{B}, \mathrm{C}, \mathrm{A}, \mathrm{M}, \mathrm{G})
\end{aligned}
$$

where $\mathrm{dw} / \mathrm{dt}=$ percentage change in employment 1971-76

$\mathrm{B}=$ core-periphery dummy variable $(1=$ core, $0=$ other $)$

A $=$ agricultural region dummy variable $(1=$ agricultural region, $0=$ other)

$\mathbf{M}=$ mining region dummy variable $(1=$ mining region, $0=$ other)
TABLE 3

Estimated Values of Regression Coefficients of Single Equation OLS Models Explaining Variations in SC Indices Based On Employment-Australian Sub-State

\begin{tabular}{|c|c|c|}
\hline \multirow[b]{2}{*}{ Independent Variable } & \multicolumn{2}{|c|}{ Dependent-Variable } \\
\hline & SCEI & SCEO \\
\hline \multicolumn{3}{|l|}{ Percentage change in } \\
\hline Employment & $-0.06^{*}$ & $-0.05+$ \\
\hline \multicolumn{3}{|l|}{ Percentage Construction } \\
\hline Employment in 1971 & $0.60^{* *}$ & $0.28 * *$ \\
\hline Core periphery position & -0.65 & -0.18 \\
\hline Agricultural region & -0.05 & 0.32 \\
\hline Mining region & $3.92^{* *}$ & 0.14 \\
\hline Growth Center region & $2.78 * *$ & $2.66+$ \\
\hline Intercept & 1.40 & 2.15 \\
\hline $\mathbf{R}^{2}$ & 0.727 & .434 \\
\hline \multicolumn{3}{|c|}{$\begin{array}{l}\text { **Significant at the one per cent level } \\
\text { *Significant at the ten per cent level } \\
\text { + Significant at the five per cent level }\end{array}$} \\
\hline $\mathrm{G}=\begin{array}{l}\mathrm{gr} \\
\mathrm{bl} \\
\mathrm{re}\end{array}$ & $\begin{array}{l}\text { nter dur } \\
=\text { grow } \\
=\text { other) }\end{array}$ & $\begin{array}{l}\text { ny varia- } \\
\text { center }\end{array}$ \\
\hline
\end{tabular}
Regions 1971-1976

Two similar models of the form

$$
\begin{aligned}
\text { SCPI } & =\mathbf{f}(\mathrm{dw} / \mathrm{dt}, \mathrm{B}, \mathrm{C}, \mathrm{A}, \mathbf{M}, \mathrm{G}) \\
\text { and SCPO } & =\mathrm{f}(\mathrm{dw} / \mathrm{dt}, \mathrm{B}, \mathrm{C}, \mathrm{A}, \mathbf{M}, \mathrm{G})
\end{aligned}
$$

were specified to explain structural change indices for employment data and people of working age not in employment.

Ordinary least squares regression estimates of the first two models appear in Table 3. The two development related variables were both significant in explaining variation in SCEI, as were the mining and growth center dummies, both incorporated to reflect the influence of local factors. The core-periphery variable representing the urban hierarchy-influence and the agricultural region dummy were not significant. Percentage change in employment and percentage in construction and employment in 1971 both were significant explanators of SCEO as was the growth center dummy.

When the population based SC measures, SCPI and SCPO are specified and estimated in a similar model the results are rather different. As can be seen from Table 4, percentage workforce growth from 1971 to 1976 is no longer significant but geographic location as reflected by the core-periphery variable is now significant in explaining both SCPI and SCPO. Now, also, the agricultural region dummy variable is 
TABLE 4

Estimated Values of Regression Coefficients of Single Equation OLS Models Explaining Variations in SC Indices Based on Population of Working Age. Australian Sub-State Regions 1971-1976

\begin{tabular}{lcc}
\hline \multicolumn{2}{c}{ Independent Variable } & Dependent-Variable \\
\multicolumn{2}{c}{ SCPI } & SCEO \\
\hline $\begin{array}{l}\text { Percentage Change in } \\
\quad \text { Employment }\end{array}$ & 0.01 & 0.001 \\
$\begin{array}{l}\text { Percentage Construction } \\
\quad \text { Employment in 1971 }\end{array}$ & $0.26^{* *}$ & $0.15^{*}$ \\
Core periphery position & 1.06 & $-.48^{* *}$ \\
Agricultural region & $1.03+$ & $1.69^{* *}$ \\
Mining region & 0.08 & -.47 \\
Growth Center region & 0.60 & $1.67^{*}$ \\
Intercept & 3.75 & 3.51 \\
R & 0.643 & 0.457 \\
\hline **Significant at the one per cent level & \\
*Significant at the ten per cent level & \\
+ Significant at the five per cent level &
\end{tabular}

highly significant and the mining region dummy is not. The larger changes in percentage unemployment and workforce participation in agricultural regions than in the major cities and mining areas support this result.

The results obtained in the first model suggest that changes in the structure of employment by industry class are significantly influenced by several variables. Change in employment has a negative sign, indicative of declining areas experiencing greater structural change. This may reflect depressed regions having outflows of labor as it seeks opportunity elsewhere, while the loss of major portions of some sectors will affect the SC measure. Peripheral regions that lose major employers will emerge as having undergone considerable structural change. One example would be the loss of employment in textiles, steel, or automobile production causing both migration and a change in the employment structure of the regional economy.

As hypothesized above, the construction variable showed greater change in those regions initially subject to major investment activity. The highly significant contribution of local factors reflected in the mining and growth-center region dummies is notable. The experience of Albury-Wodonga from 1971 to 1976, and subsequently, suggests that growth-center initiatives may be worthwhile.

While the significance of percentage employment change, initial construction employment and growth center activity require little further comment in discussing the SCEO model, the non-significance of the mining dummy is notable. Residents in mining regions experienced less change in their occupational employment profile than their industry employment situation. Many were clearly able to apply their occupational skills in a different industry sector.

As might be expected from preliminary analysis of Tables 1 and 2, the population based models produced rather different results to those based on employment alone. Change in employment was no longer a significant explanator of either of the SC measures but coreperiphery and agricultural region dummies now exert an significant explanatory influence.

The negative sign for the core variable means that there was less change in core regions, reflecting smaller population change in more diverse economies. Core region industries showed less change as they are more advanced and less likely to suffer during recession, while changing participation rates and migration would also operate to produce greater movements for peripheral areas. The construction variable was again significant, although the coefficient was not as large. Agricultural areas experienced large increases in participation rates as women entered the workforce, and in unemployment-largely among the youngwhich contributed much more to their SCPO values than mining areas. The populations of mining regions are probably more mobile and, as can be implied from the final column of Table 1 , appeared more capable of "exporting" their potential unemployment problems.

\section{Conclusions}

The passage of structural change in regional context is a complex process. Its occurrence and relationship to regional development is an area which demands continuing study by academics and policy makers. In an era when many national economies are chronically troubled with problems of inflation, unemployment, and slow growth, the regional consequences of structural change vary widely. The experience of Western economies during the seventies supports this contention. For Australia the summary SC measures indicate that the passage of structural change in labor markets in sub-state regions was uneven. Much of this variation is explainable in terms of differences in initial 
economic development, location and local factors.

Regional development is frequently seen in terms of improved welfare or reduced inequality, yet experience in many countries has shown that even in a growing economy these objectives have been difficult to achieve. In a period characterized by recession the problem is even greater, for the disadvantaged or peripheral region may no longer claim a portion of national growth, as occurred in the past; these areas must compete more strongly to achieve the levels of the past or face diminished levels of well being. Results have pointed to locational factors as being significant, and this illustrates a foundation of regional analysis; that access and location account for much of the national distribution of economic activity and regional economic structure, for this factor contains the operation of the hierarchy as well as market access.

If objectives of regional equality and development are to be maintained, then it is important to reconsider policy for use in a no-growth environment.

\section{FOOTNOTES}

'For a summary of official activity see Lloyd, p. 78. Two notable meetings by professional bodies were the 1978 Autumn Forum of the Victorian Branch of the Economic Society of Australia and New Zealand, and the 1980 Annual Conference of the Regional Science AssociationAustralian and New Zealand section.

2Thompson (p. 49) gives an alternative insight into the process involved in his flow chart illustrating patterns of urban-regional economic development.

${ }^{3}$ An equivalent measure is discussed by Isard, p. 254. He points out that it has been used in various forms since the mid-1930's.

${ }^{4}$ In computing SCEI, percentages of total employed persons are used. By contrast, in computing SCPI, percentages of the total population of working age, i. e. the sum of total employed persons, unemployment and people not in the workforce, are used.

${ }^{5}$ Compilation of percentages in computing SCEO and SCPO are based on total employed persons and the total population of working age respectively.

'One might argue that secular change may also have influenced the percentage level of construction employment during the 1971-1976 period. Because of the relatively short period of the analysis we have assumed that such change is minimal.

\section{REFERENCES}

Australian Government. Bureau of Census and Statistics, 1971 Census of Population and Housing, Characteristics of Population and Dwellings, Local Government Areas. Canberra, 1973.

Australian Government. Department of Urban and Regional Development. Regions, Canberra, 1973.

Australian Government. Australian Bureau of Statistics, 1976 Census of Population and Housing, Characteristics of Population and Dwellings. Local Government areas. Canberra, 1978.

Australian Government. Study Group on Structural Adjustment Report March 1979, Canberra, 1979.

Dolley, Colin, "Some Regional Implications of Structural Change," Economic Activity, 23(2), (April, 1980), 2-9.

Isard, W. and associates, Methods of Regional Analysis, Cambridge, Mass.; M.I.T. Press, 1960.

Lloyd, P.J., "International Pressures and Structural Change in Australia: An Overview," Economic Papers, 59, (August, 1978), 75-91.

Mansfield, E., The Economics of Technological Change, London: Longman, 1969.

Maxwell, P. and Demetrious, J., "Structural Change in Sub-State Regional Labour Markets: A Case Study of Western Australia," Economic Activity, 24(3), (July, 1981), 2-9.

Pred, A., City Systems in Advanced Economies, London: Hutchinson, 1977.

Schiavo-Campo, S., "The Simple Measurement of Structural Change: A Note," Economic Record, 54 (August, 1978), 261-263.

Stanback, T.M. and Knight, R.V., The Metropolitan Economy, New York: Columbia U.P., 1970

Thompson, W. R., A Preface to Urban Economics, Baltimore: Johns Hopkins U.P. 1968.

Wilde, P.D., "Industrial Change and Employment Problems in Tasmania," Australian Bulletin of Labour, 5(3), (June, 1979), 36-54. 